\title{
Transcriptomic signatures of peroxisome proliferator-activated receptor a (PPARa) in different mouse liver models identify novel aspects of its biology
}

\author{
Ewa Szalowska ${ }^{1 *}$, Haftu A Tesfay ${ }^{1,2}$, Sacha A F T van Hijum³ and Sander Kersten ${ }^{2 *}$
}

\begin{abstract}
Background: The peroxisome proliferator-activated receptor alpha (PPARa) is a ligand-activated transcription factor that regulates lipid catabolism and inflammation and is hepatocarcinogenic in rodents. It is presumed that the functions of PPARa in liver depend on cross-talk between parenchymal (hepatocytes) and non-parenchymal (Kupffer and endothelial cells) fractions as well as inter-organ interactions. In order to determine how cellular composition and inter-organ interactions influence gene expression upon pharmacological activation of PPARa, we performed a meta-analysis of transcriptomics data obtained from mouse hepatocytes (containing only the parenchymal fraction), mouse liver slices (containing both fractions), and mouse livers exposed to a PPARa agonist. The aim was to obtain a comprehensive view of common and model-specific PPARa-dependent genes and biological processes to understand the impact of cross-talk between parenchymal and non-parenchymal fractions as well as the effect of inter-organ interactions on the hepatic PPARa transcriptome.

To this end we analyzed microarray data of experiments performed in mouse primary hepatocytes treated with the PPARa agonist Wy14643 for 6 or 24 h (in vitro), mouse precision cut liver slices treated with Wy 14643 for 24 h (ex vivo), and livers of wild type and Ppara knockout mice treated with Wy14643 for 6 h or 5 days (in vivo).

Results: In all models, activation of PPARa significantly altered processes related to various aspects of lipid metabolism. In ex vivo and in vivo models, PPARa activation significantly regulated processes involved in inflammation; these processes were unaffected in hepatocytes. Only in vivo models showed significant regulation of genes involved in coagulation, carcinogenesis, as well as vesicular trafficking and extracellular matrix.

Conclusions: PPARa-dependent regulation of genes/processes involved in lipid metabolism is mostly independent of the presence of non-parenchymal cells or systemic factors, as it was observed in all liver models. PPARa-dependent regulation of inflammatory genes requires the presence of non-parenchymal cells, as it was observed only ex vivo and in vivo. However, the full spectrum of PPARa biology at the level of lipid metabolism, immunity, carcinogenesis, as well as novel aspects of PPARa signaling such as coagulation, vesicular trafficking and the extracellular matrix, seems to require systemic factors, as it was observed exclusively in vivo.
\end{abstract}

Keywords: Peroxisome proliferator-activated receptor alpha (PPARa), Fibrates, Lipid metabolism, Inflammation, Parenchymal and non-parenchymal liver cells, Mouse liver models, Transcriptomics

\footnotetext{
*Correspondence: eszalow@gmail.com; sander.kersten@wur.nl

'RIKILT - Institute of Food Safety, Wageningen UR, P.O. Box 230, 6700 AE

Wageningen, The Netherlands

${ }^{2}$ Nutrition, Metabolism and Genomics Group, Wageningen University,

Bomenweg 2, 6703 HD Wageningen, The Netherlands

Full list of author information is available at the end of the article
}

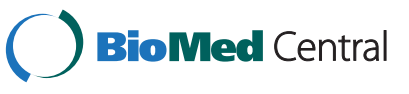

(c) 2014 Szalowska et al.; licensee BioMed Central. This is an Open Access article distributed under the terms of the Creative Commons Attribution License (http://creativecommons.org/licenses/by/4.0), which permits unrestricted use, distribution, and reproduction in any medium, provided the original work is properly credited. The Creative Commons Public Domain Dedication waiver (http://creativecommons.org/publicdomain/zero/1.0/) applies to the data made available in this article, unless otherwise stated. 


\section{Background}

Peroxisome proliferators, which include insecticides, herbicides, surfactants, phthalates, organic solvents, and hypolipidemic/anti-inflammatory fibrate drugs, were discovered as chemicals that upon administration to rodents increase the number of liver peroxisomes, stimulate fatty acid catabolism, and after chronic exposure cause hepatomegaly and hepatocarcinogenesis [1]. The effects of peroxisome proliferators are mediated by the peroxisome proliferator-activated receptor $\alpha$ (PPAR $\alpha)$ [2]. PPAR $\alpha$, together with PPAR $\delta$ and PPAR $\gamma$, forms a small subfamily of PPARs within the superfamily of nuclear receptors [3]. Similarly to other nuclear receptors, PPAR $\alpha$ acts as a heterodimer with the retinoid $\mathrm{X}$ receptor and occupies specific DNA sequences referred to as PPAR response elements. Binding of a ligand to PPAR $\alpha$ leads to the dissociation of co-repressors and the association of co-activators necessary for the activation of transcription. In mice, PPAR $\alpha$ has the highest expression level in liver and brown adipose tissue, followed by a lower expression in kidney, heart, and intestine [4]. The physiological role of PPAR $\alpha$ in liver is to govern lipid metabolism. In particular during starvation, activation of PPAR $\alpha$ leads to stimulation of fatty acid (FA) uptake, mitochondrial $\beta$-oxidation, peroxisomal FA oxidation, and ketogenesis [5,6]. In addition, PPAR $\alpha$ controls lipoprotein metabolism [7-10]. Due to the role of PPAR $\alpha$ in maintenance of lipid homeostasis, it has become an important molecular target for dyslipidemia [11]. In addition, PPAR $\alpha$ ligands and dual PPAR $\alpha / P P A R \delta$ ligands are being explored for the treatment of nonalcoholic fatty liver disease [12].

Apart from its profound role in regulation of lipid metabolism, PPAR $\alpha$ exerts anti-inflammatory and antiatherogenic effects, which may be beneficial in the treatment of several metabolic diseases associated with inflammation such as non-alcoholic steatohepatitis and atherosclerosis $[11,13]$. The anti-inflammatory actions of PPAR $\alpha$ are mediated via its negative interference with other nuclear factors such as the NF-kB, AP-1, C/EBP, and STAT proteins, which govern innate and adaptive immunity $[14,15]$. In the liver, hepatocytes likely are the major cell type mediating the anti-inflammatory effects of PPAR $\alpha$, since no PPAR $\alpha$ was detected in rat liver resident macrophages i.e. Kupffer cells [16,17]. In addition to hepatocytes, PPAR $\alpha$ is expressed in other relevant immune cells such as dendritic cells, non-hepatic macrophages, as well as $\mathrm{B}$ and $\mathrm{T}$ lymphocytes, which can infiltrate the liver during development of metabolic disorders. Accordingly, these cells are potential therapeutic targets for PPAR $\alpha$ ligands to manage hepatic inflammation [18-20]. PPAR $\alpha$ is also expressed in non-hepatic vascular cells, likely accounting for the effects of synthetic PPAR $\alpha$ agonists on angiogenesis [21,22], endothelial permeability [23], and vascular adhesion capacity
[11], which are important in the treatment of atherosclerosis. However, it is questionable whether PPAR $\alpha$ agonists can directly affect hepatic endothelial cell gene expression, because mouse and rat endothelial cells do not express PPAR $\alpha[16,17,24]$.

Although PPAR $\alpha$ is expressed in the liver parenchymal fraction (i.e. hepatocytes) and is not or very weakly expressed in the rodent non-parenchymal liver fraction (i.e. Kupffer cells and endothelial cells) $[16,17,24]$, it is presumed that interactions between both fractions as well as inter-organ interactions are necessary to fulfill hepatic PPAR $\alpha$ functions related to regulation of lipid metabolism and immunity. In order to determine how cellular composition and inter-organ interactions influence gene expression upon PPAR $\alpha$ activation, we performed a meta-analysis of transcriptomics data obtained from relevant mouse liver models represented by mouse primary hepatocytes (containing only the parenchymal fraction) treated with the PPAR $\alpha$ agonist Wy14643 for 6 or $24 \mathrm{~h}$ (in vitro), precision cut liver slices (containing both parenchymal and non-parenchymal fractions) treated with Wy14643 for $24 \mathrm{~h}$ (ex vivo), and livers of wild type (WT) and Ppara knockout (KO) mice treated with Wy14643 for 6 h or 5 days (in vivo). The aim was to obtain a comprehensive view of common and model-specific PPAR $\alpha$-dependent genes and biological processes to understand the impact of the cross-talk between parenchymal and non-parenchymal fractions as well as the effect of inter-organ interactions on the hepatic PPAR $\alpha$ transcriptome. In addition, we aimed to assess the performance of in vitro and ex vivo liver models to study the PPAR $\alpha$ transcriptome in relation to the in vivo situation.

\section{Methods}

\section{Chemicals}

Wy14643 was obtained from ChemSyn Laboratories (Lenexa, KS). Recombinant human insulin (Actrapid) was obtained from Novo Nordisk (Copenhagen, Denmark). DMEM, fetal calf serum, calf serum, and penicillin/ streptomycin/fungizone were obtained from Lonza Bioscience (Verviers, Belgium). Williams E medium supplemented with Glutamax, penicillin/streptomycin (pen/strep), D-glucose, phosphate buffered saline (PBS) were obtained from Invitrogen (Invitrogen, Bleiswijk, The Netherlands). Otherwise, chemicals were obtained from Sigma (Zwijndrecht, The Netherlands).

\section{Mouse primary hepatocytes (in vitro liver model)}

Mouse hepatocytes were prepared and used in experiments have been described previously [25]. Briefly, the hepatocytes were isolated by two-step collagenase perfusion from 6 different strains of mouse; NMRI, SV129, FVB, DBA, BALB/C and C57BL/6. The mouse strains differed with respect to age (2-6 months) and gender 
(female or male) [25]. Cells were plated on collagencoated six-well plates. Cell viability was determined by Trypan Blue exclusion, and was at least 75\%. Hepatocytes obtained for 6 different mouse strains were cultured independently in William's E medium (Lonza Bioscience, Verviers, Belgium) supplemented with $10 \%$ (v/v) fetal calf serum, $20 \mathrm{~m}$-units/mL insulin, $10 \mathrm{nM}$ dexamethasone, $100 \mathrm{U} / \mathrm{mL}$ penicillin, $100 \mathrm{mg} / \mathrm{mL}$ of streptomycin, 0.25 $\mathrm{mg} / \mathrm{mL}$ fungizone and $50 \mathrm{mg} / \mathrm{mL}$ gentamycin. After four hours the medium was discarded and replaced with fresh medium. The next day, cells were incubated in fresh medium in the presence or absence of Wy14643 $(10 \mu \mathrm{M})$ dissolved in dimethyl sulfoxide (DMSO) for 6 and $24 \mathrm{~h}$, followed by RNA isolation. Isolation of mouse primary hepatocytes was approved by the Ethical Committee for Animal Experiments of Wageningen University.

\section{Precision cut liver slices (ex vivo liver model)}

Precision cut liver slices (PCLS) were prepared and cultured as described previously [26]. Briefly, livers from 6 months old C57BL/6 mice were perfused with saline, excised and submerged in ice-cold Krebs-Henseleit Buffer (KHB) supplemented with $11 \mathrm{mM}$ glucose, $25 \mathrm{mM}$ sodium bicarbonate, $10 \mathrm{mM}$ 4-(2-hydroxyethyl)-1-piperazineethanesulfonic acid (HEPES), and penicillin/streptomycin. The livers were collected at 11 a.m. (ZT5). Next, 5 mm cylindrical liver cores were prepared with a surgical biopsy punch and sectioned to $200 \mu \mathrm{m}$ slices using a Krumedieck tissue slicer (Alabama Research and Development, Munford, AL, USA) filled with carbonated KHB. Liver slices were incubated in William's E Medium (Lonza, Verviers, Belgium) in 6 -well plates at $37^{\circ} \mathrm{C} / 5 \% \mathrm{CO}_{2} / 80 \%$ $\mathrm{O}_{2}$ under continuous shaking. After 1 hour the media was replaced with fresh William's E Medium in the presence or absence of Wy14643 $(20 \mu \mathrm{M})$ dissolved in dimethyl sulfoxide (DMSO). After $24 \mathrm{~h}$ incubation, samples were snap-frozen in liquid nitrogen and stored in $-80^{\circ} \mathrm{C}$ for RNA isolation. PCLS were obtained from four mice and were cultured independently per each experimental condition i.e. $n=4$ for Wy14643 and $n=4$ for DMSO.

\section{Animals (in vivo liver model)}

In vivo treatment with Wy4643 has been described previously [27]. Briefly, male wildtype and Ppara-KO mice on a Sv129 background were used at 3-5 months of age (Jackson Laboratories, Bar Harbor, ME). Animals were fed normal laboratory chow (RMH-B diet, Arie Blok animal feed, Woerden, the Netherlands). During acute pharmacological activation of PPAR $\alpha$ by Wy14643, wildtype and Ppara-KO mice fasted for 4 hours received a single dose of Wy14643 (400 $\mu \mathrm{L}$ of $10 \mathrm{mg} / \mathrm{mL}$ Wy14643 dissolved in $0.5 \%$ carboxymethylcellulose) and were killed 6 hours later ( $n=5$ per group). During chronic pharmacological activation of PPAR $\alpha$ by Wy14643, WT and Ppara-KO mice were fed with Wy14643 for 5 days by mixing it in their food $(0.1 \%, n=5$ per group). Livers from the acute pharmacological activation of PPAR $\alpha$ were collected at $\sim 3$ p.m. (ZT9) and livers from the chronic activation of PPAR $\alpha$ were collected at 11 a.m. (ZT5). Livers from all experiments were dissected and immediately frozen in liquid nitrogen for RNA isolation. All animal experiments were approved by the Ethical Committee for Animal Experiments of Wageningen University.

\section{RNA isolation}

Total RNA was extracted from primary hepatocytes using TRIzol reagent (Invitrogen, Breda, The Netherlands) and RNA was further purified using RNeasy micro columns (Qiagen, Venlo, the Netherlands).

Prior to RNA isolation, PCLS were homogenized with a tissue homogenizer Precellys 24 Bertin Technologies (Labmakelaar Benelux B.V. Rotterdam, The Netherlands) using settings: $2 \mathrm{x}\left(15 \mathrm{sec}, 6500 \mathrm{~g}, 8^{\circ} \mathrm{C}\right)$. Next, total RNA was isolated using the RNeasy Tissue Mini Kit (Qiagen, Venlo, The Netherlands) according to manufacturer's protocols.

Total RNA was extracted from mouse livers using TRIzol reagent (Invitrogen, Breda, The Netherlands), and purified and DNAse treated using the SV Total RNA Isolation System (Promega, Leiden, The Netherlands).

RNA concentration and purity were assessed spectrometrically using a Nano Drop ND-1000 spectrophotometer (Isogen, IJsselstein, The Netherlands). RNA quality was assessed on an Agilent 2100 bioanalyzer (Agilent Technologies, Amsterdam, the Netherlands). Only RNA samples that met quality criteria (i.e. RNA Integrity Number >8.0) were used for array hybridization experiments. For primary hepatocytes, purified RNA (500 ng) was used for one cycle cRNA synthesis (Affymetrix, Santa Clara, CA). Hybridization of samples derived from primary hepatocytes was performed on Affymetrix Gene chip mouse genome 4302.0 arrays. Purified RNA (100 ng) isolated from PCLS was labeled with the Ambion WT expression kit (Life Technologies, Bleiswijk, The Netherlands) and hybridized to Affymetrix Mouse Gene 1.1 ST array plate (Affymetrix, Santa Clara, CA). RNA isolated from mouse livers $(5 \mu \mathrm{g})$ was used for one cycle cRNA synthesis (Affymetrix, Santa Clara, CA) and hybridized to Affymetrix Genechip mouse genome 4302.0 arrays (wildtype and Ppara-KO treated with Wy14643 or vehicle for 6 hours as well as wildtype and Ppara-KO treated with Wy14643 or vehicle for 5 days). Hybridization, washing, and scanning of all Affymetrix Genechips was according to standard Affymetrix protocols. Scans of the Affymetrix arrays were processed using the Bioconductor package [28]. The microarray data obtained from the above mentioned experiments were deposited to gene expression omnibus (GEO). The GEO series accession 
numbers are as follows: GSE17250 (primary hepatocytes obtained from 6 different mouse strains treated with Wy14643 or vehicle, $\mathrm{n}=6$ per group), GSE8292 (WT and Ppara-KO treated with Wy14643 or vehicle for 6 hours, $\mathrm{n}=3-5$ per group), and GSE8295 (WT and Ppara-KO treated with Wy14643 or vehicle for 5 days, $\mathrm{n}=4$ per group). The accession number for the microarray of precision cut liver slices is pending.

\section{Statistical analysis of microarray data}

Expression levels of probe sets were calculated using Robust Multiarray Averaging (RMA) with m-estimator summarization and remapped in Common Data Format (CDF) version 17.0.1 [29]. Identification of differentially expressed genes was performed using Rank Products (RP). False discovery rates were determined by RP using 1000 permutations of the samples. Genes with a false discovery rate $(\mathrm{FDR}) \leq 0.05$ were considered as significant [30]. All comparisons were made between treatments and controls (i.e. Wy14643 vs. vehicle).

\section{Gene ontology analysis -DAVID}

The significantly up- and down-regulated genes by the treatments (i.e. Wy14643) were uploaded separately to the Database for Annotation, Visualization, and Integrated Discovery (DAVID) Bioinformatics Resource. In DAVID the Functional Annotation Clustering tool generated clusters of up- or down- overrepresented Gene Ontology (GO) terms [31,32]. The Mouse Genome 430 2.0 was used as a background for the GO analysis of the in vitro, ex vivo, and in vivo hepatic models. After correction for FDR $\leq 0.005$ (Benjamini Hochberg), the GO terms were selected for further analysis and interpretation.

\section{Venn diagram analysis}

Venn diagram analysis of the significantly affected genes identified in our study was performed using VENNY [33].

\section{Pearson's correlation analysis}

Pearson's correlation analysis was performed using IBM SPSS Statistics 20 and the results are presented as scatterplots using Microsoft Excel 2010.

\section{Results}

\section{Identification of differentially expressed genes}

In order to identify genes significantly altered by pharmacological PPAR $\alpha$ activation, we analyzed microarray data of different liver models (i.e. in vitro, ex vivo, and in vivo) treated with the synthetic PPAR $\alpha$ agonist Wy14643 using Rank Products (RP) [30]. The use of Wy14643 was justified by the observation that changes in in vivo hepatic gene expression elicited by Wy14643 and another common PPAR $\alpha$ agonist fenofibrate were extremely similar (Additional file 1). Only genes that were overlapping between different types of microarray chips used in our study were included in the analysis. In general it was observed that the number of significantly altered genes increased with increasing complexity of the liver model (with regard to duration of the treatment and cellular composition of the model) (Figure 1). Thus, in primary hepatocytes treated with Wy14643 for $6 \mathrm{~h}$ and $24 \mathrm{~h}, 68$ and 93 genes were upregulated, respectively. In liver slices, 117 genes were significantly upregulated by Wy14643, and in livers of mice exposed to Wy14643 for $6 \mathrm{~h}$ and 5 days, 487 and 978 genes were significantly upregulated, respectively. Very few genes were downregulated by PPAR $\alpha$ activation in primary hepatocytes, whereas 61, 391 and 794 genes were significantly downregulated by Wy14643 treatment in liver slices, mouse livers treated for $6 \mathrm{~h}$, and mouse livers treated for 5 days, respectively.

\section{Relevance of in vitro and ex vivo models for the in vivo situation}

To determine the resemblance between "simpler" liver models (i.e. in vitro and ex vivo) vs. the more complex models (i.e. in vivo), Venn diagram analysis of genes significantly regulated in each model was performed. The analysis showed that there was a substantial overlap between the "simpler" hepatic models and the in vivo models, Figure 2A-C.

Additionally, to evaluate whether Wy14643 affected gene expression in the same direction in in vitro/ex vivo versus in vivo models, and to compare the magnitude of fold changes in each model, Pearson's correlation analysis was performed (Figure 3). In the analysis we separately compared expression changes of genes significantly upregulated $(\mathrm{FDR} \leq 0.05)$ in primary hepatocytes and liver slices after Wy14643 treatment with expression changes of the corresponding genes in vivo. Interestingly, we observed that the majority of the genes analyzed were commonly upregulated between in vitro/ ex vivo and in vivo experiments. The magnitude of gene expression changes was generally higher in vivo compared to in vitro and ex vivo (Figure 3A-F).

The same type of analysis was performed for the significantly downregulated genes $(F D R \leq 0.05)$ identified ex vivo, i.e. expression of genes significantly downregulated in liver slices was compared with expression changes of the corresponding genes in vivo. Surprisingly, out of 61 significantly downregulated genes in liver slices, only 23 and 31 corresponding genes were changed in the same direction in livers of mice treated with Wy14643 for $6 \mathrm{~h}$ and 5 days, respectively, while the remaining genes were unaltered or upregulated in vivo compared to ex vivo. In general, fold changes of the commonly downregulated genes were lower in liver slices compared to livers in vivo (Figure 3G-H). Due to 


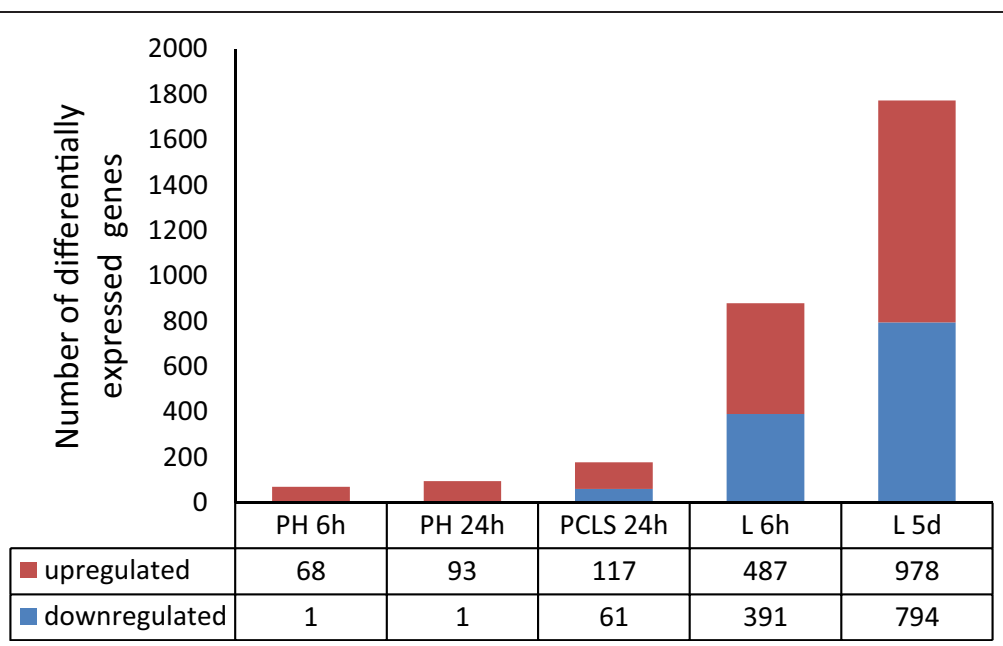

Figure 1 Effect on hepatic gene expression during activation of PPARa. The total number of significantly up- and down-regulated genes $(F D R \leq 0.05)$ identified in primary hepatocytes treated with Wy 14643 for 6 or 24 h ( $\mathrm{PH} 6 \mathrm{~h}$ or PH 24 h), precision cut liver slices treated with Wy14643 for 24 h (PCLS 24 h), livers of mice treated with Wy 14643 for 6 h of 5 days (L6h or L5d).

the absence of significantly downregulated genes in primary hepatocytes, no correlation analysis was performed for this model.

\section{Gene ontology analysis}

In order to obtain a comprehensive view of the biological processes affected by Wy14643 in different liver models, significantly up- and down-regulated genes were subjected to GO analysis using DAVID [32,34]. The GO analysis of the upregulated genes by Wy14643 in all liver models revealed that several GO terms related to different aspects of lipid catabolism such as "fatty acid metabolic process" and "acyl-CoA metabolic process" were significantly enriched in almost all hepatic models, except for "lipid localization" and "peroxisomes organization", which were found only in vivo (Figure 4A). However, GO terms related to cell proliferation/tumorgenesis and other aspects of lipid metabolism were significantly enriched only in livers of mice exposed to Wy14643 for 5 days (Figure 4B).

The GO analysis performed for the significantly downregulated genes showed that GO terms related to different aspects of immunity were significantly enriched in both ex vivo and in vivo models (Figure 5A). GO terms exclusively detected in livers of mice exposed to Wy14643 for 5 days were related to immunity, coagulation, protein/amino acid metabolism, metabolism of organic compounds as well as GO processes nominated as "oxidation reduction". "steroid metabolic process",
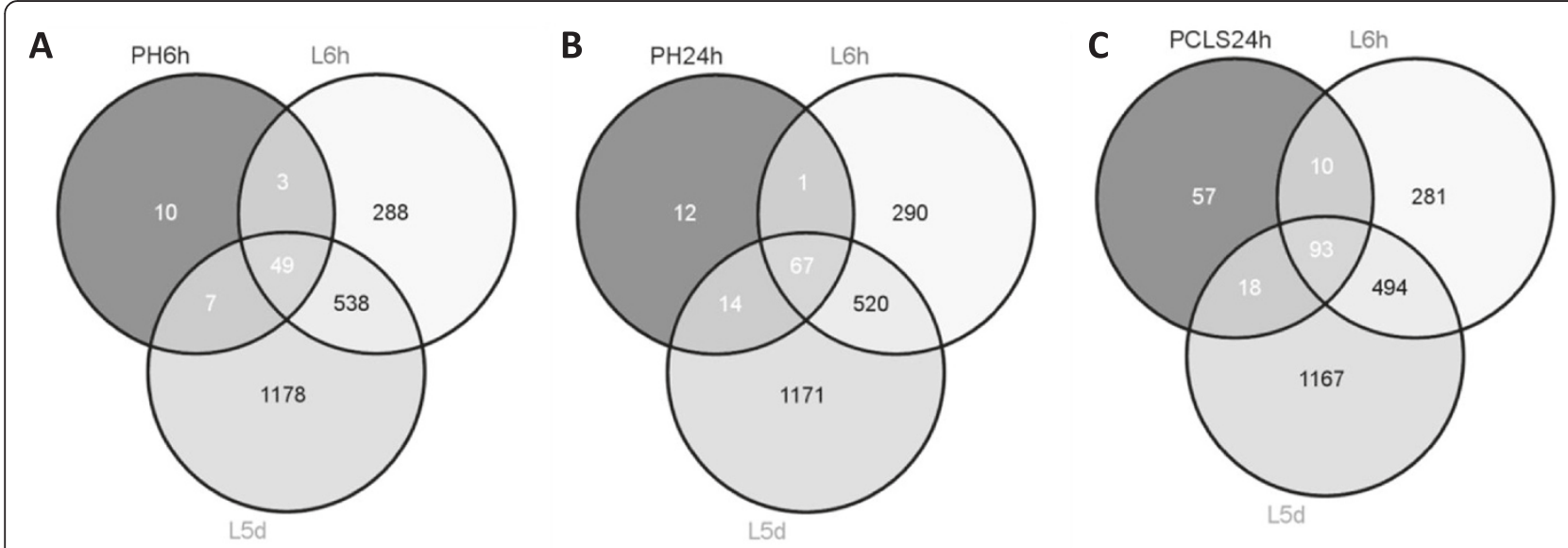

Figure 2 Venn diagram analysis. Venn diagram analysis of the significant genes (FDR $\leq 0.05$ ) identified in "simpler" models represented by (A) primary hepatocytes treated with Wy14643 for 6 h (PH 6 h), (B) primary hepatocytes treated with Wy 14643 for 24 h (PH 24 h), and (C) precision cut liver slices treated with Wy14643 for 24 h (PCLS 24 h) vs. significant genes (rank products, FDR $\leq 0.05$ ) identified in in vivo models represented by livers of mice exposed to Wy14643 for $6 \mathrm{~h}$ (L6h) and livers of mice exposed to Wy14643 for 5 days (L5d). 


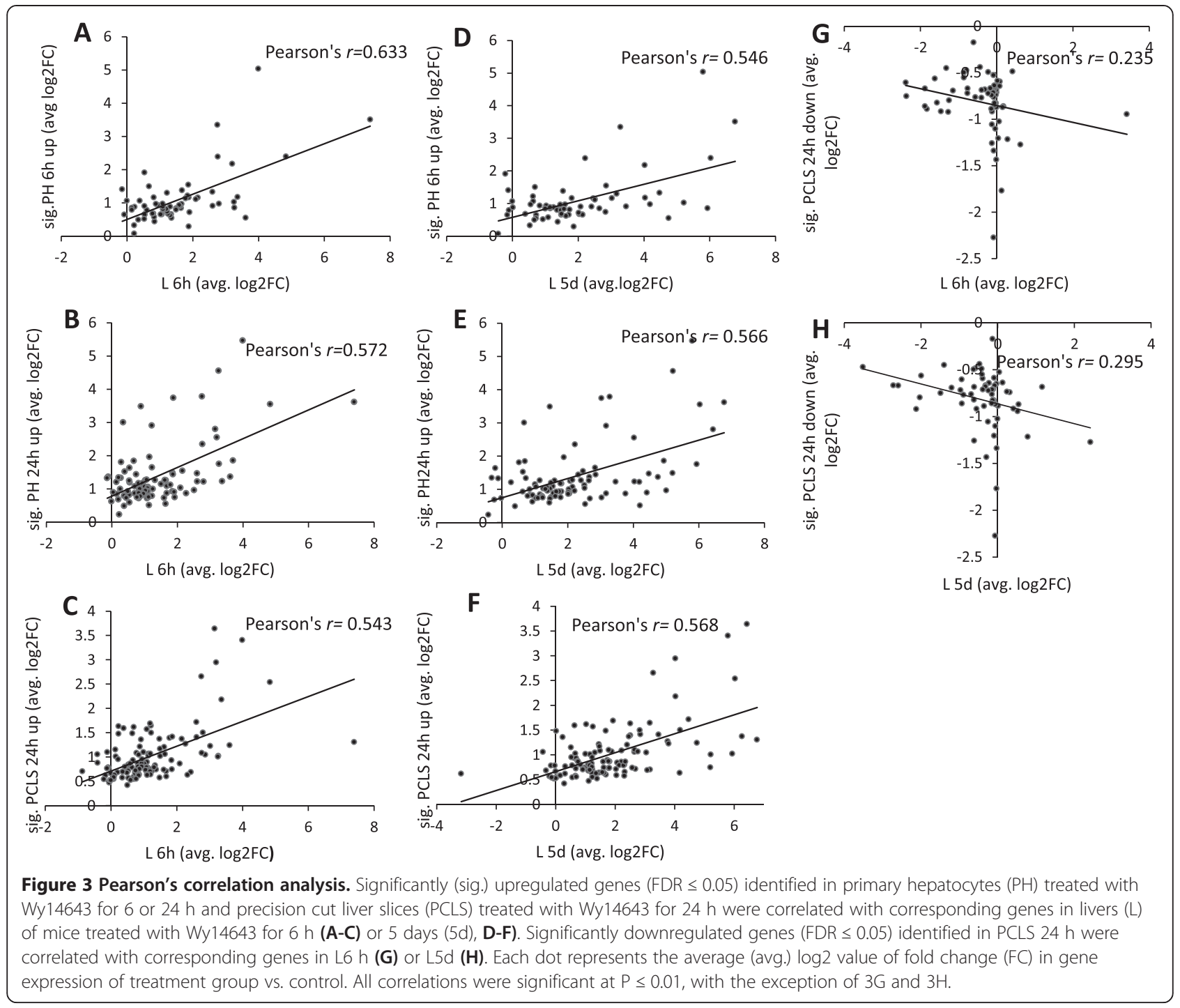

"hemostasis", "regulation of body fluid levels", "bile acid metabolic process", "lipid localization", and "lipid transport" (Figure 5B).

\section{"PPARa-tailored analysis"}

Due to the fact that the GO analysis resulted in functional annotation of only a sub-fraction of the total number of significant genes ( $\sim 25 \%$ genes per liver model $)$, an additional functional analysis, referred to as "PPAR $\alpha$-tailored analysis", was performed. The incentive for this additional analysis was to annotate a higher number of genes than via GO analysis and assign genes to novel and more detailed functional categories. The "PPAR $\alpha$-tailored analysis" was performed gene by gene using the open access database GeneCards. GeneCards provides current genomic, proteomic, genetic, transcriptomic, and functional information on all known and predicted genes. The selection of genes for the "PPAR $\alpha$-tailored analysis" was rather subjective; we considered all significant genes that were overlapping between at least two hepatic models (Figure 6A-B). Eventually we considered 370 unique upregulated genes (out of 1120 unique genes upregulated in all hepatic models) and 224 unique downregulated genes (out of 991 unique genes downregulated in all hepatic models). The aim behind such a selection was to focus on the most relevant genes for PPAR $\alpha$ signaling across all liver models and at the same time reduce the total number of genes analyzed. We only analyzed genes that are regulated in a PPAR $\alpha$-dependent manner. Thus genes that were significantly regulated by Wy14643 treatment in both wildtype and Ppara-KO were excluded from the "PPAR $\alpha$-tailored analysis". Using GeneCards we were able to functionally annotate 227 (out of 370 upregulated) and 125 (out of 224 downregulated) genes, which were divided into up- and down-regulated functional categories (Additional files 2, 3 and 4). As part of the "PPAR $\alpha$-tailored analysis", genes related to lipid 


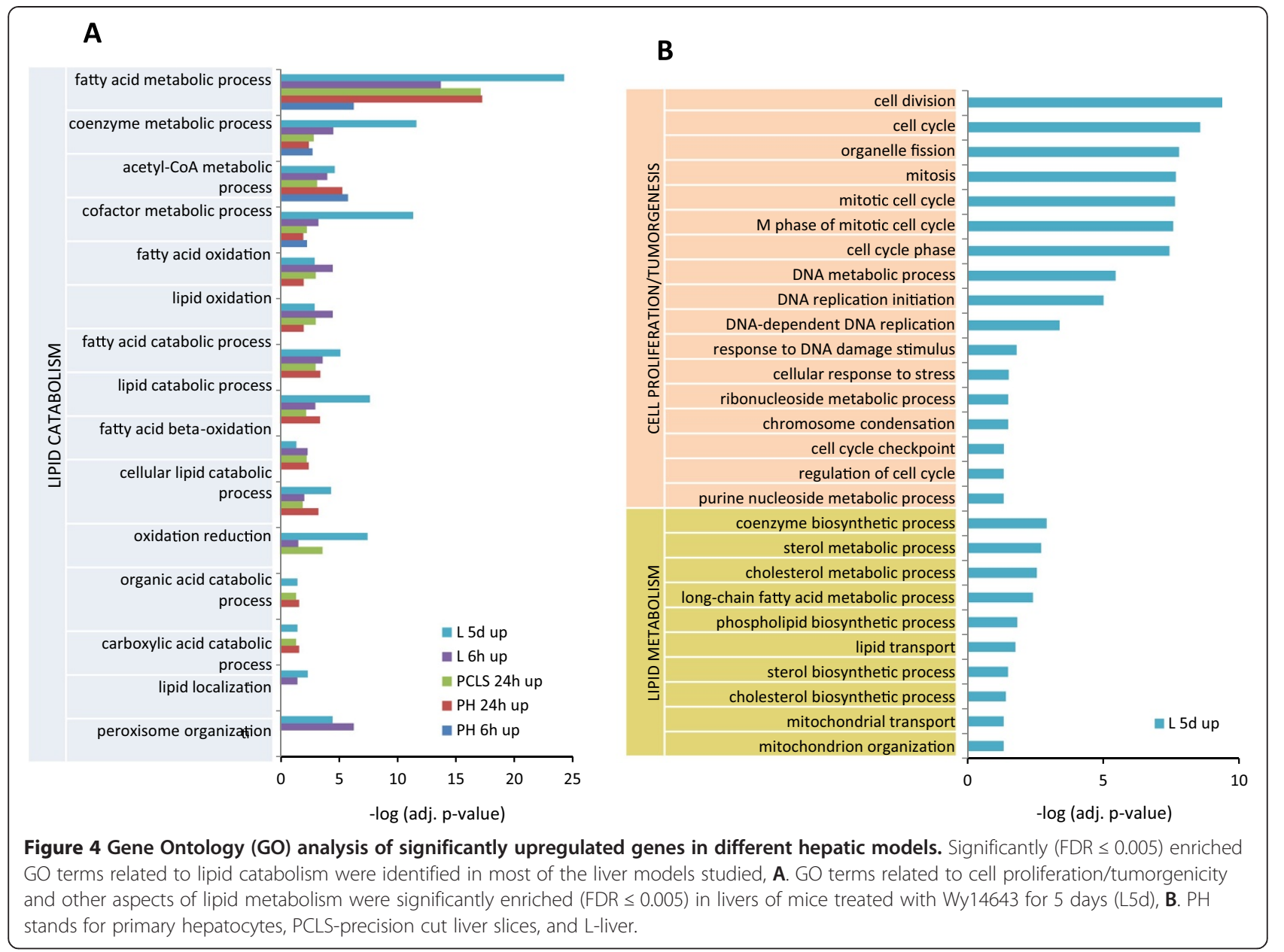

catabolism were categorized into "peroxisomal $\beta$ oxidation", "peroxisomal membrane \& biogenesis", and "mitochondrial carriers" and these categories, similarly to the results from GO analysis, contained significantly upregulated genes in all liver models (Additional file 2). However, the more complex the hepatic model, the higher the number of significant genes and their fold change. As in GO analysis, a gene functional category related to tumorgenesis (i.e. cell cycle) contained genes that were significantly upregulated only in in vivo models (Additional file 3).

In comparison to GO analysis, the "PPAR $\alpha$-tailored analysis" led to the identification of additional upregulated functional categories such as "extracellular matrix" (ECM), "cytoskeleton", "endothelial functions", "integrity of Golgi", "vesicular trafficking", "endocytosis", and "neurotransmission". Genes belonging to these categories were significantly upregulated almost exclusively in vivo (Additional files 2 and 3). Downregulated functional categories such as "acute phase" or "coagulation" contained genes that were significantly downregulated mostly in vivo; only few genes within these categories were also significantly downregulated in liver slices (e.g. F11, Orm2, Orm3, and Crp) (Additional file 3). In addition, compared to GO analysis, the "PPAR $\alpha$-tailored analysis" identified novel downregulated gene functional categories such as "transcriptional co-repression/ activation", "NF-кB (downstream activation)", "immunity", "T and B cells functions", "angiogenesis", "ECM", "cytoskeleton", and "neurotransmission". Genes belonging to these categories were significantly and nearly exclusively downregulated in vivo, with the exception of a few genes that were also significantly downregulated ex vivo and none of these genes were significantly altered in vitro (Additional file 4).

In general, the results of the "PPAR $\alpha$-tailored analysis" were in line with the statistical and GO analyses and revealed that the most significant changes occurred in vivo, followed by ex vivo, and the least changes occurred in in vitro models. However, compared to $\mathrm{GO}$ analysis, the "PPAR $\alpha$-tailored analysis" annotated a higher percentage of the analyzed genes (i.e. $\sim 50 \%$ vs. $\sim 25 \%$ respectively) as well as identified additional and novel PPAR $\alpha$-related functional categories. A summary of the results of the 'PPAR $\alpha$ - tailored analysis' is presented in Figure 7. 
A

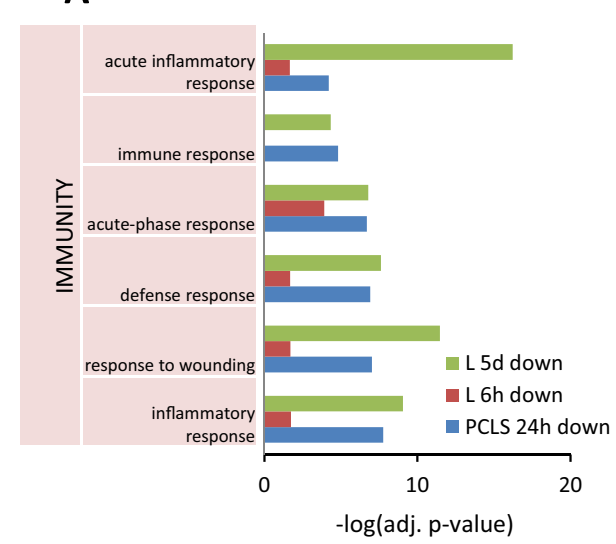

B

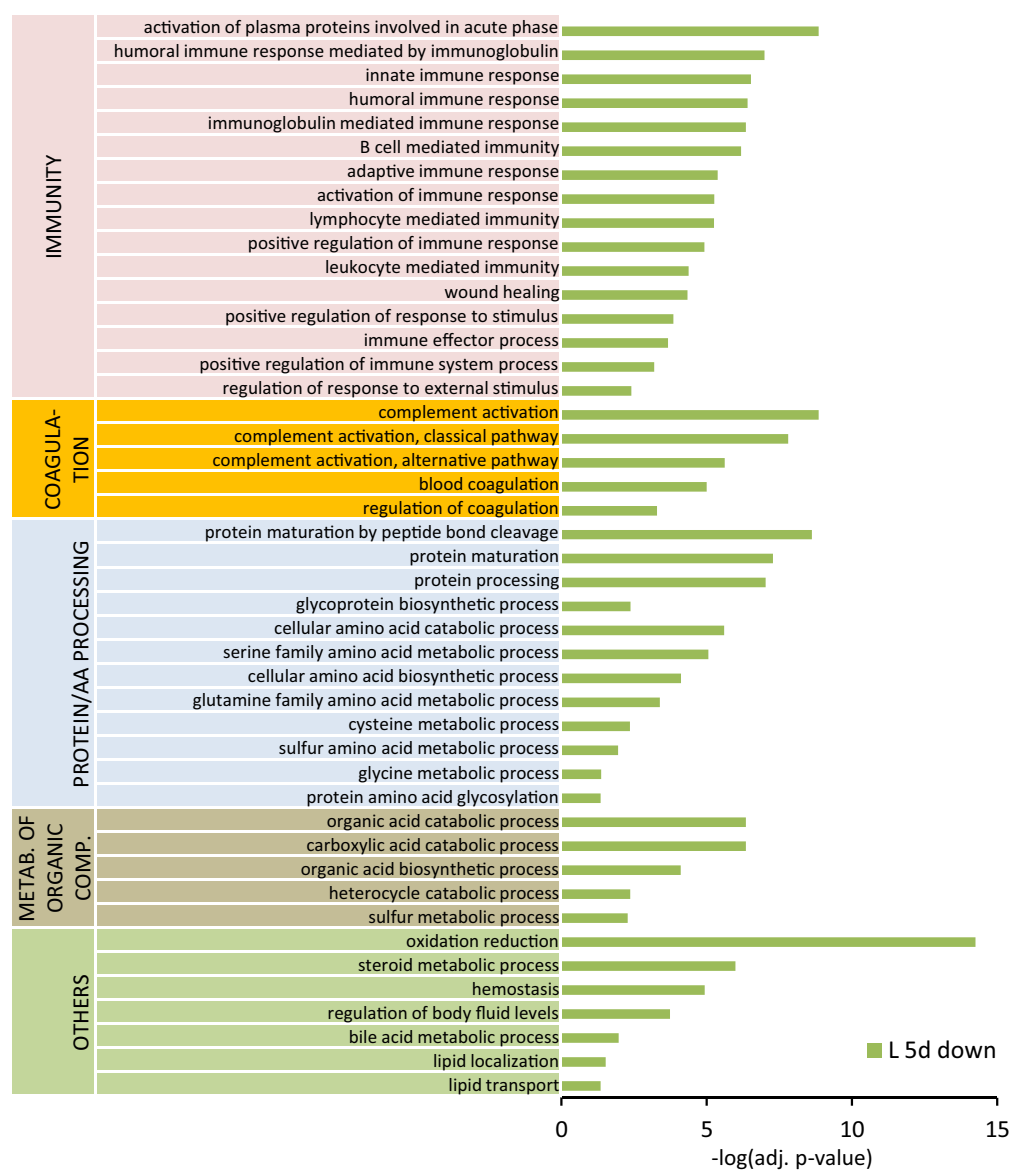

Figure 5 Gene Ontology (GO) analysis of significantly downregulated genes in different hepatic models. Significantly (FDR $\leq 0.005$ ) enriched GO terms related to different aspects of immunity were identified in liver slices treated with Wy14643 for $24 \mathrm{~h}$ (PCLS $24 \mathrm{~h})$ and livers of mice treated with Wy14643 for $6 \mathrm{~h}(\mathrm{~L} 6 \mathrm{~h})$ or 5 days $(\mathrm{L} 5 \mathrm{~d}), \mathrm{A}$. GO terms related to other aspects of immunity, coagulation, protein/amino acid (aa) metabolism, metabolism of organic compounds, and others were significantly (FDR $\leq 0.005)$ enriched only in livers of mice treated with Wy 14643 for 5 days $(L 5 d), \mathbf{B}$.

\section{Integrated concept of PPARa signaling during its pharmacological activation}

Biological processes identified in the meta-analysis were integrated into a simplified concept of hepatic PPAR $\alpha$ signaling under not-inflamed conditions (Figure 8). We propose that during activation of PPAR $\alpha$, significant regulation of genes related to "ECM" and "cytoskeleton" as well as "endothelial functions", "endocytosis", "Golgi", and "vesicular trafficking" might facilitate sudden influx and traffic of FA to hepatocytes and target organelles such as nucleus, mitochondria, and peroxisomes. At the same time, activation of PPAR $\alpha$ leads to immunosuppression caused by downregulation of genes related to "NF- $\mathrm{kB}$ signaling", "coagulation", "acute phase", and "immunity", likely to suppress an immune response elicited by massive traffic of potentially cytotoxic FA [35]. Finally, pharmacological activation of PPAR $\alpha$ affects genes involved in "neurotransmission".

\section{Discussion}

The challenge in meta-analyses is to circumvent the variation of independent microarray experiments and extract biologically relevant information [36]. The metaanalysis of hepatic PPAR $\alpha$ signaling performed in our study is mostly based on separate microarray experiments that were generated over several years and originally served a different purpose than this study $[25,27]$. Variations in the experimental set up used to generate these microarray data are: use of different types of Affymetrix gene chips, different batches of chemicals, unequal number of biological replicates per group, differences in time of exposure to Wy14643 and model-specific concentration of Wy14643. Furthermore, there were differences related to age, gender, and mouse strains, which all together could increase experimental variation and hamper the identification of genuine biological effects. However, the experiments were performed on the same platform, by 

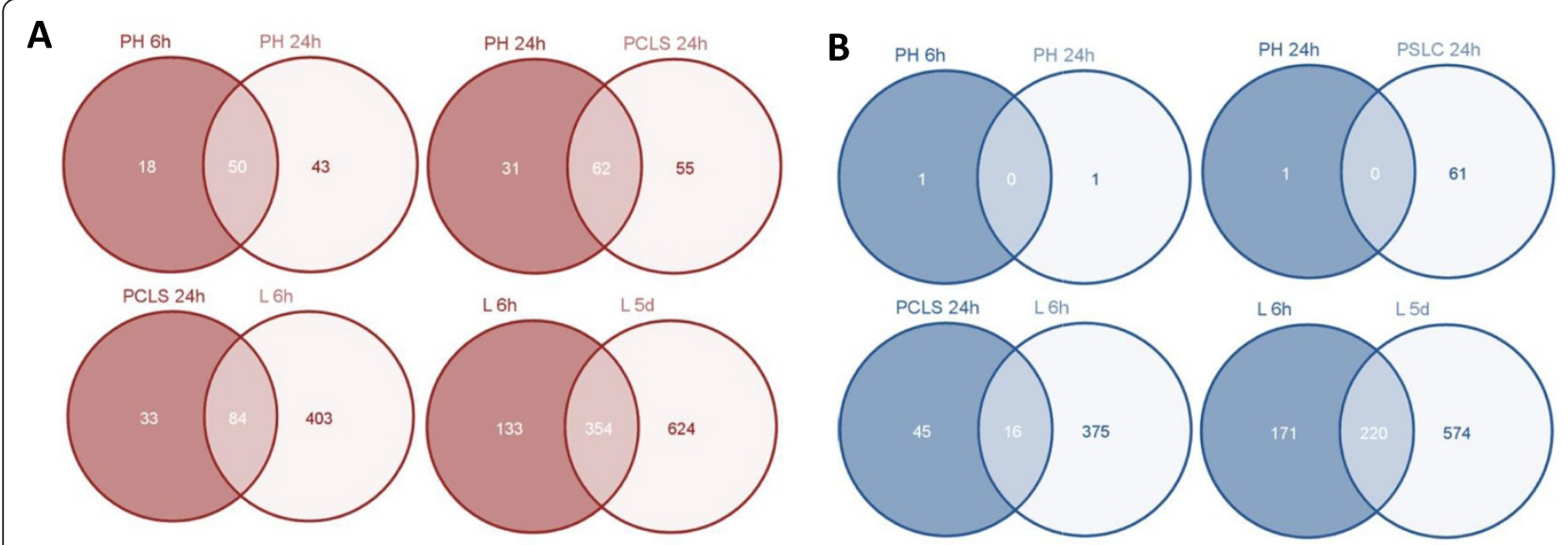

Figure 6 Gene selection for the "PPARa tailored analysis". Genes selected for the "PPARa tailored analysis" consisted of significantly up- and down-regulated genes (FDR $\leq 0.05)$ that were overlapping between at least two liver models. Numbers of overlapping up- and down-regulated genes are presented in $\mathbf{A}$ and $\mathbf{B}$ respectively. PH 6 h/24 h stands for primary hepatocytes treated with Wy 14643 for 6 or 24 h, PCLS 24 h-precision cut liver slices treated with Wy14643 for 24 h, and L6 h/5d-liver treated with Wy14643 for 6 h of 5 days.

the same technician, and standard procedures were used over the years.

To minimize the effects of the above-mentioned experimental differences, and to allow identification of biologically relevant significant genes, we applied the RP approach. The RP approach is a powerful statistical method to analyze microarray data generated from relatively few replicates, performed in different laboratories and/or using different platforms. Moreover, RP outperformed other statistical tests applied in meta-analyses such as t-based approach and Fisher's Inverse $x^{2}$ method [30,36,37].

In our study, we identified a variable number of significantly up- and down-regulated genes in different liver models. The number of significantly regulated genes corresponded with the complexity of the hepatic model determined by time of exposure, cellular composition, and the absence/presence of systemic effects (i.e. inter-organ interactions). Thus, the lowest number of significantly upregulated genes was found in primary hepatocytes and in this model very few genes were significantly downregulated. This finding contradicts with our previous analysis in which we identified more than 400 up- and down-regulated genes in primary hepatocytes after 6 and $24 \mathrm{~h}$ treatment with Wy14643 [25]. This discrepancy can be explained by the application of different statistical methods in both studies, i.e. the former study used a Linear Models for Microarray Data without correction for FDR. In contrast, we applied a more stringent RP that corrects for FDR $[25,28,30]$.

The very low number of downregulated genes in primary hepatocytes may be explained by the absence of the non-parenchymal fraction, which is an abundant source of pro-inflammatory factors [38]. Although it was shown that activation of PPAR $\alpha$ can suppress the immune response and downregulate gene expression in hepatocytes by antagonizing the NF- $\mathrm{KB}$ signaling pathway, the relevant experiments were performed in the presence of pro-inflammatory stimuli [14]. In contrast, our experiments in hepatocytes were performed under non-inflamed conditions, which may explain the very low number of significantly downregulated genes. In agreement with our results, a study performed in rat liver and rat primary hepatocytes treated with PPAR $\alpha$ ligands showed that downregulation of (proinflammatory) genes occurred only in vivo [39].

In order to evaluate the relevance of in vitro and ex vivo models for the in vivo situation, we performed a comparative analysis of the significantly altered genes in each model by means of Venn diagrams. In addition, Pearson's correlation analysis was performed to compare the direction of changes in gene expression in in vitro and ex vivo models vs. the in vivo situation. The results of Venn diagram analysis showed substantial similarities between "simpler" liver models and the in vivo models, suggesting that primary hepatocytes and liver slices are relevant models to study pharmacological activation of PPAR $\alpha$ in vivo. With regard to the results of Pearson's correlation analysis, it revealed that almost all genes upregulated in vitro and ex vivo, were also upregulated in vivo. In contrast, only a small fraction of genes downregulated ex vivo was downregulated in vivo. These results indicate that primary hepatocytes and liver slices are valid liver models to study genes induced by activation of PPAR $\alpha$ with Wy14643, but less suitable to study genes downregulated by activation of PPAR $\alpha$ with Wy14643. This finding was unexpected and suggests that downregulation of genes by PPAR $\alpha$ is model-dependent. Inasmuch as the cellular composition of liver slices is comparable to the liver in vivo, i.e. both models contain parenchymal and non-parenchymal cells [40], these 


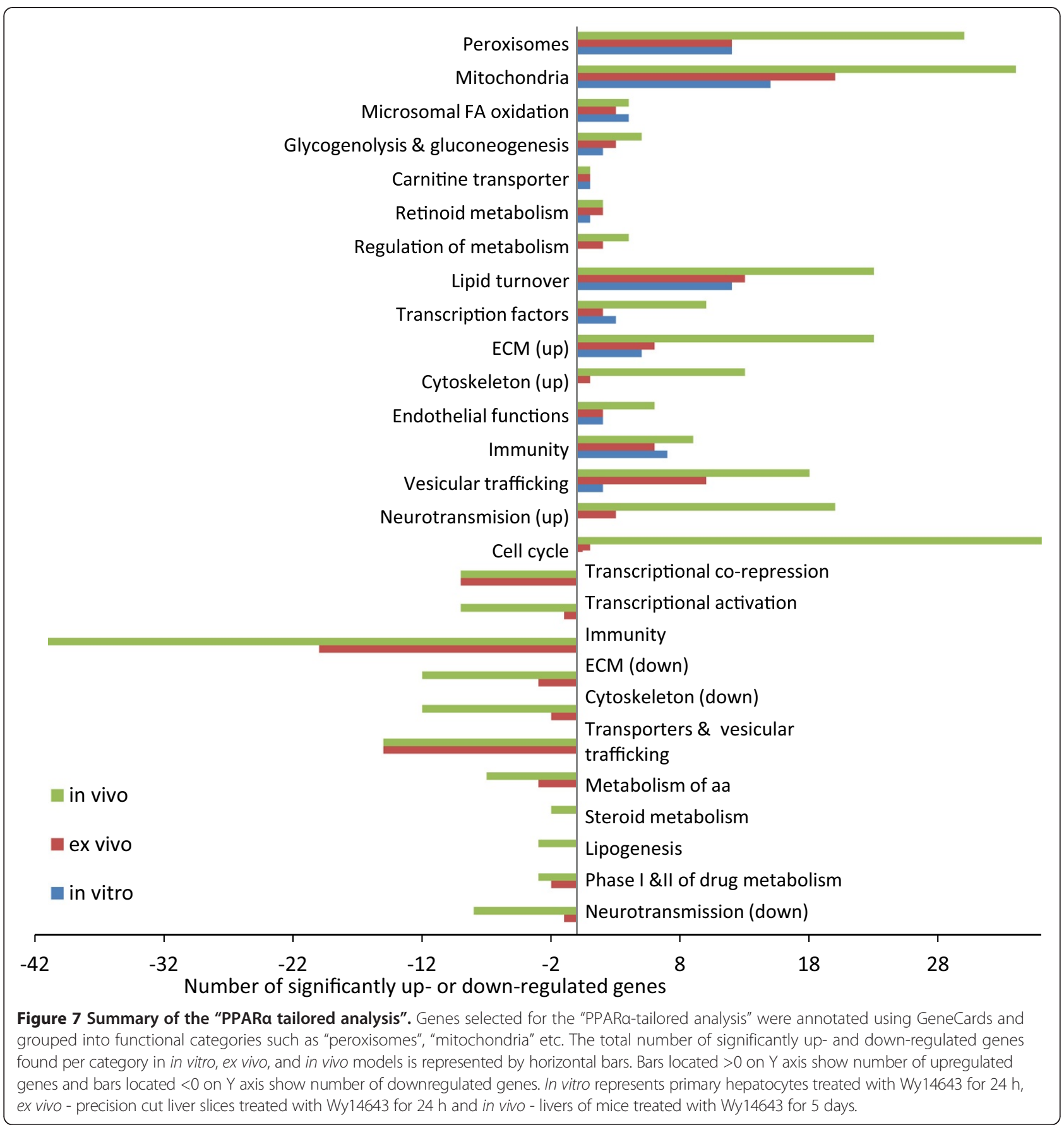

differences may be explained by systemic effects that are obviously absent ex vivo.

In all liver models, lipid metabolism emerged as a dominant pathway regulated by PPAR $\alpha[25,27]$. Despite the fact that there is a cross-talk between parenchymal and non-parenchymal fractions in regulation of hepatic lipid metabolism [41-43], we did not observe striking differences in regulation of genes involved in lipid metabolism between our in vitro and ex vivo models, suggesting that the presence of non-parenchymal cells does not affect the Wy14643-mediated regulation of genes involved in lipid metabolism. Genes related to lipid metabolism were induced most significantly (in terms of number and fold change) in vivo, indicating that lipid metabolism is more sensitive to regulation in vivo compared to in vitro and ex vivo models. However, it can't be ruled out that our results are biased by the lack of standardization of conditions across all liver 


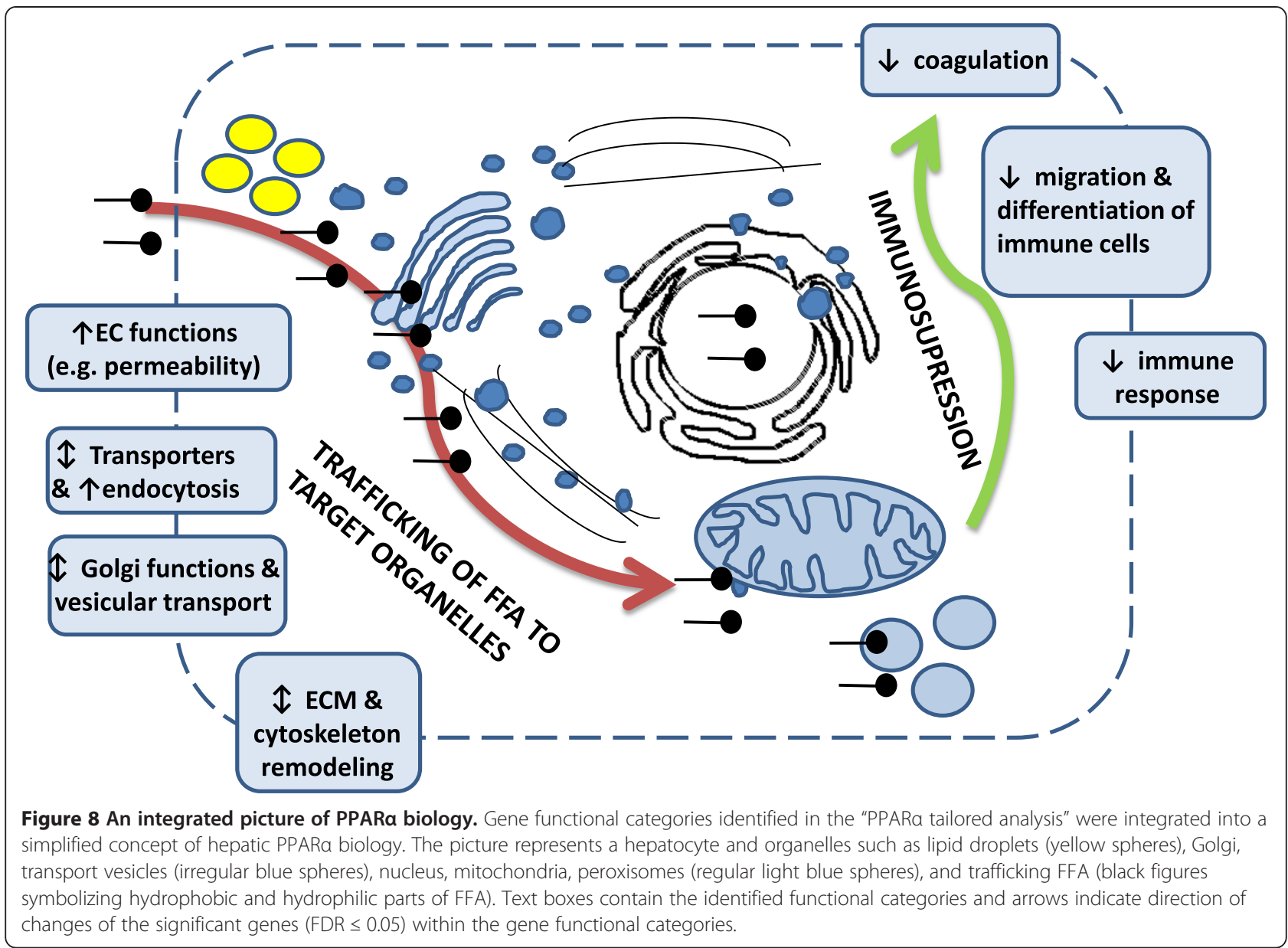

models in relation to differences in concentration of glucose, insulin, or other biomolecules, which could also affect lipid metabolism.

Next to the identification of processes related to different aspects of lipid catabolism, the "PPAR $\alpha$-tailored analysis" identified genes, mostly in vivo, that could be assigned into novel functional categories not previously linked to PPAR $\alpha$, such as "ECM", "cytoskeleton", "endothelial functions", "integrity of Golgi", "vesicular trafficking", and "endocytosis". Given the key role of PPAR $\alpha$ in regulation of hepatic lipid metabolism, we hypothesize that genes belonging to these novel categories might somehow be linked to transport, traffic, and catabolism of FA during activation of PPAR $\alpha$ by Wy14643. It is possible that during pharmacological activation of PPAR $\alpha$, FA and TG carried by lipoproteins and albumin freely pass fenestrated hepatic endothelial cells [27,44]. In hepatocytes, FA are taken up by transporters [45], followed by poorly defined trafficking of FA to target organelles such as mitochondria and peroxisomes to undergo oxidation. Consistent with this picture, we hypothesize that genes categorized as "endothelial functions" and "endocytosis" could be involved in transfer of FA through the endothelium, exemplified by the known PPAR $\alpha$ target Angptl4, which plays a role in vascular permeability [46]. In addition, Adtrp, Nrpt, E2f8 could also modulate endothelial permeability via interaction with Vegf-b [47]. Next, the traffic of FA to target organelles might be governed by genes in categories denoted as "ECM", "cytoskeleton", "integrity of Golgi", "endocytosis", and "vesicular trafficking". This notion is in line with an emerging concept of vesicular transport of FA to target organelles and cells co-occurring with reorganization of ECM, cytoskeleton, and Golgi [48]. Interestingly, similar functional categories have been linked to PPAR $\beta / \delta$ in pancreatic $\beta$-cells including granule biosynthesis, intra-cellular vesicle trafficking, and exocytosis [49]. Therefore, it could be hypothesized that all PPARs may play a role in traffic of certain molecules in and out of the cell.

In addition to the above mentioned processes, several $\mathrm{GO}$ processes and genes related to different aspects of immunity were significantly downregulated only in ex vivo and in vivo models (Figure 5, Additional file 3). These findings are in concordance with the known anti- 
inflammatory properties of PPAR $\alpha[11,14]$. However, in our study, due to the lack of inflammation, it seems to be more appropriate to refer to these processes as immunosuppression. Immunosuppression was not observed in primary hepatocytes, suggesting that interaction with immune mediators and/or immune cells (e.g. Kupffer cells) is essential.

Another novel gene functional category identified in this study exclusively in vivo is denoted as "neurotransmission". Currently, there is a scarce evidence for a crosstalk between PPAR $\alpha$ and the nervous system. However, recently it was shown that stimulation of the vagus nerve increased plasma endogenous PPAR $\alpha$ ligands cooccurring with upregulation of hepatic PPAR $\alpha$ expression and systemic anorectic effects [50]. Another study showed that hepatic PPAR $\alpha$ activation led to glucocorticoidinduced insulin resistance and hypertension via an afferent vagal nerve pathway [51]. It is possible, therefore, that activation of PPAR $\alpha$ by Wy14643 affects neurosignaling to coordinate liver metabolism with other organs and tissues to maintain energy homeostasis.

Finally, in accordance with the known hepatocarcinogenic effect of peroxisomes proliferators in rodents [52], we found that activation of PPAR $\alpha$ significantly upregulated several genes related to cell proliferation in vivo. Surprisingly, this effect was absent in our in vitro and ex vivo liver models. Given the fact that Wy14643 induces DNA synthesis in rat hepatocytes after 48 hours, but not 24 hours [53], it can be speculated that the 24 hours Wy14643 treatment in our in vitro model might be too short to detect the proliferative/carcinogenic changes. Previously it was reported that treatment of mouse primary hepatocytes with peroxisomes proliferators (including Wy14643) for 24 hours led to upregulation of 11 genes related to liver cancer (i.e. Angptl4, Bnip3, Dbi, Fabp1, Fabp2, Fasn, Hifla, Lgals3, Ly6d, Mgll, SerpineI) [54]. However, it has to be stressed that none of these genes is strictly related to cell proliferation/ carcinogenesis [GeneCards]. Consistent with the notion that Kupffer cells play a central role in peroxisome proliferator-induced carcinogenesis, it was found that genes related to cell proliferation are induced by PPAR $\alpha$ ligands in rat liver but not in primary rat hepatocytes [39].

Our observation that treatment of liver slices with Wy14643 did not alter genes related to cell proliferation conflicts with the finding that peroxisomes proliferators induced DNA synthesis in rodent co-cultures of hepatocytes with non-parenchymal cells $[41,53]$. A possible explanation for this discrepancy might be that to assess proliferative/carcinogenic properties of peroxisomes proliferators, measuring DNA synthesis is more appropriate than analysis of genes related to cell proliferation. Unfortunately, we cannot make a comparison of our gene expression data obtained in liver slices with gene expression obtained in other relevant rodent liver models, due to the lack of such data.

\section{Conclusions}

In summary, this study provides a comprehensive picture of gene expression during pharmacological activation of PPAR $\alpha$ by Wy14643 in different mouse hepatic models under not-inflamed conditions. PPAR $\alpha$-dependent regulation of many genes and processes involved in lipid metabolism is mostly independent of the presence of nonparenchymal cells or inter-organ interactions, as it was observed in all liver models. PPAR $\alpha$-dependent regulation of inflammatory genes requires the presence of nonparenchymal cells, because it was observed only ex vivo and in vivo. However, the full spectrum of PPAR $\alpha$ biology at the level of lipid metabolism, immunity, carcinogenesis, as well as novel aspects of PPAR $\alpha$ signaling such as coagulation, vesicular trafficking and the extracellular matrix, seems to require systemic factors, as it was observed exclusively in vivo.

Although in vitro and ex vivo systems turned out to be relevant liver models to study the PPAR $\alpha$ transcriptome compared to the in vivo situation, liver slices behaved as an intermediate model between in vitro and in vivo, and thus represent a superior replacement for primary hepatocytes.

\section{Additional files}

Additional file 1: A comparative analysis of gene expression by Wy14643 and fenofibrate in mouse liver. Global gene expression data obtained from samples representing livers of mice treated for $6 \mathrm{~h}$ with Wy14643 or fenofibrate were expressed as fold change calculated as ratio of gene expression in treatment group ( $\mathrm{n}=4$ or 5 ) vs. gene expression in control group $(n=4)$.

Additional file 2: PPARa tailored gene functional analysis (upregulation). Significantly upregulated genes that were overlapping between at least two hepatic models were selected for a functional analysis using an open access database GeneCards. Based on the provided information, the selected genes were grouped into functional categories and analyzed in each hepatic model i.e. primary hepatocytes treated with Wy14643 for 6 h or 24 h (PH 6H or PH 24 h), precision cut liver slices treated with Wy14643 for 24 h (PCLS 24 h), and livers of mice treated with Wy14643 for 6 h or 5 days (L6h or L5d). Genes that were significantly altered are depicted in bold and underlined, red color indicates upregulation, black no change, and green downregulation of gene expression. Fold change was calculated as the average gene expression value in treatment group vs. control.

Additional file 3: PPARa tailored gene functional analysis (upregulation). Significantly upregulated genes that were overlapping between at least two hepatic models were selected for a functional analysis using an open access database GeneCards. Based on the provided information, the selected genes were grouped into functional categories and analyzed in each hepatic model i.e. primary hepatocytes treated with Wy14643 for 6h or $24 \mathrm{~h}$ ( $\mathrm{PH} 6 \mathrm{H}$ or $\mathrm{PH} 24$ h), precision cut liver slices treated with Wy14643 for 24 h (PCLS 24 h), and livers of mice treated with Wy 14643 for 6 h or 5 days (L6h or L5d). Genes that were significantly altered are depicted in bold and underlined, red color indicates upregulation, black no change, and green downregulation of 
gene expression. Fold change was calculated as the average gene expression value in treatment group vs. control.

\section{Additional file 4: PPARa tailored gene functional analysis}

(downregulation). Significantly downregulated genes that were overlapping between at least two hepatic models were selected for a functional analysis using an open access database GeneCards. Based on the provided information, the selected genes were grouped into functional categories and analyzed in each hepatic model i.e. primary hepatocytes treated with Wy14643 for 6 h or 24 h ( $\mathrm{PH} 6 \mathrm{H}$ or $\mathrm{PH} 24$ h), precision cut liver slices treated with Wy14643 for 24h (PCLS 24 h), livers of mice treated with Wy14643 for 6 h or 5 days (L6h or L5d). Genes that were significantly altered are in bold and underlined, red color indicates upregulation, black no change, and green downregulation. Fold change was calculated as the average gene expression value in treatment group vs. control.

\section{Abbreviations}

PPARa: Peroxisome proliferator-activated receptor alpha; FA: Fatty acids; PBS: Phosphate buffered saline; DMSO: Dimethyl sulfoxide; KHB: Krebs-Henseleit Buffer; HEPES: (4-(2-hydroxyethyl)-1-piperazineethanesulfonic acid); PCLS: Precision cut liver slices; KO: Knockout; WT: Wild type; GO: Gene Ontology; DAVID: The Database for Annotation, Visualization, and Integrated Discovery; RP: Rank products; FDR: False discovery rate; RMA: Robust Multiarray Averaging; CDF: Common Data Format; ECM: Extracellular matrix.

\section{Competing interests}

The authors declare that they have no competing interests.

\section{Authors' contributions}

ESZ designed the study, analyzed data, and wrote the manuscript. HAT performed experiments. SAFTVH provided bioinformatics tools and support as well as critically read the manuscript. SK contributed microarray datasets and edited the manuscript. All authors read and approved the final manuscript.

\section{Acknowledgements}

We would like to thank Mark Boekschoten for pre-processing of microarray data. This work was financially supported by Wageningen University and Research.

\section{Author details}

${ }^{1}$ RIKILT - Institute of Food Safety, Wageningen UR, P.O. Box 230, 6700 AE Wageningen, The Netherlands. ${ }^{2}$ Nutrition, Metabolism and Genomics Group, Wageningen University, Bomenweg 2, 6703 HD Wageningen, The Netherlands. ${ }^{3} \mathrm{CMBI}$ Centre for Molecular and Biomolecular Informatics, Bacterial Genomics Group, Radboudumc, PO Box 9101, 6500 HB Nijmegen, The Netherlands.

\section{Received: 15 August 2014 Accepted: 1 December 2014}

Published: 15 December 2014

\section{References}

1. Reddy JK, Moody DE, Azarnoff DL, Tomarelli RM: Hepatic effects of some [4-chloro-6-(2,3-xylidino)-2-pyrimidinylthio] acetic acid (WY-14,643) analogs in the mouse. Arch Int Pharmacodyn Ther 1977, 225(1):51-57.

2. Issemann I, Green S: Activation of a member of the steroid hormone receptor superfamily by peroxisome proliferators. Nature 1990, 347(6294):645-650.

3. Kersten S, Desvergne B, Wahli W: Roles of PPARs in health and disease Nature 2000, 405(6785):421-424.

4. Kliewer SA, Forman BM, Blumberg B, Ong ES, Borgmeyer U, Mangelsdorf DJ, Umesono K, Evans RM: Differential expression and activation of a family of murine peroxisome proliferator-activated receptors. Proc Natl Acad SCi U S A 1994, 91(15):7355-7359.

5. Kersten S, Seydoux J, Peters JM, Gonzalez FJ, Desvergne B, Wahli W: Peroxisome proliferator-activated receptor alpha mediates the adaptive response to fasting. J Clin Invest 1999, 103(11):1489-1498.

6. Leone TC, Weinheimer CJ, Kelly DP: A critical role for the peroxisome proliferator-activated receptor alpha (PPARalpha) in the cellular fasting response: the PPARalpha-null mouse as a model of fatty acid oxidation disorders. Proc Natl Acad Sci U S A 1999, 96(13):7473-7478.

7. Linden D, Lindberg K, Oscarsson J, Claesson C, Asp L, Li L, Gustafsson M, Boren J, Olofsson SO: Influence of peroxisome proliferator-activated receptor alpha agonists on the intracellular turnover and secretion of apolipoprotein (Apo) B-100 and ApoB-48. J Biol Chem 2002, 277(25):23044-23053.

8. Ameen C, Edvardsson U, Ljungberg A, Asp L, Akerblad P, Tuneld A, Olofsson $\mathrm{SO}$, Linden D, Oscarsson J: Activation of peroxisome proliferator-activated receptor alpha increases the expression and activity of microsomal triglyceride transfer protein in the liver. J Biol Chem 2005, 280(2):1224-1229.

9. Costet P, Legendre C, More J, Edgar A, Galtier P, Pineau T: Peroxisome proliferator-activated receptor alpha-isoform deficiency leads to progressive dyslipidemia with sexually dimorphic obesity and steatosis. J Biol Chem 1998, 273(45):29577-29585.

10. Linden D, Alsterholm M, Wennbo H, Oscarsson J: PPARalpha deficiency increases secretion and serum levels of apolipoprotein B-containing lipoproteins. J Lipid Res 2001, 42(11):1831-1840.

11. Zambon A, Gervois P, Pauletto P, Fruchart JC, Staels B: Modulation of hepatic inflammatory risk markers of cardiovascular diseases by PPAR-alpha activators: clinical and experimental evidence. Arterioscler Thromb Vasc Biol 2006, 26(5):977-986.

12. Staels $B$, Rubenstrunk $A$, Noel B, Rigou G, Delataille $P$, Millatt $L$, Baron $M$, Lucas A, Tailleux A, Hum DW, Ratziu V, Cariou B, Hanf R: Hepato-protective effects of the dual PPARalpha/delta agonist GFT505 in rodent models of NAFLD/NASH. Hepatology 2013, 58(6):1941-1952.

13. Wahli W, Michalik L: PPARs at the crossroads of lipid signaling and inflammation. Trends Endocrinol Metab 2012, 23(7):351-363.

14. Delerive P, Fruchart JC, Staels B: Peroxisome proliferator-activated receptors in inflammation control. J Endocrino/ 2001, 169(3):453-459.

15. Gervois P, Vu-Dac N, Kleemann R, Kockx M, Dubois G, Laine B, Kosykh V, Fruchart JC, Kooistra T, Staels B: Negative regulation of human fibrinogen gene expression by peroxisome proliferator-activated receptor alpha agonists via inhibition of CCAAT box/enhancer-binding protein beta. J Biol Chem 2001, 276(36):33471-33477.

16. Hoekstra M, Kruijt JK, Van Eck M, Van Berkel TJ: Specific gene expression of ATP-binding cassette transporters and nuclear hormone receptors in rat liver parenchymal, endothelial, and Kupffer cells. J Biol Chem 2003, 278(28):25448-25453.

17. Peters JM, Rusyn I, Rose ML, Gonzalez FJ, Thurman RG: Peroxisome proliferator-activated receptor alpha is restricted to hepatic parenchymal cells, not Kupffer cells: implications for the mechanism of action of peroxisome proliferators in hepatocarcinogenesis. Carcinogenesis 2000, 21(4):823-826.

18. Daynes RA, Jones DC: Emerging roles of PPARs in inflammation and immunity. Nat Rev Immunol 2002, 2(10):748-759.

19. Eheim A, Medrikova D, Herzig S: Immune cells and metabolic dysfunction. Semin Immunopathol 2014, 36(1):13-25.

20. Jones DC, Ding X, Daynes RA: Nuclear receptor peroxisome proliferatoractivated receptor alpha (PPARalpha) is expressed in resting murine lymphocytes. The PPARalpha in T and B lymphocytes is both transactivation and transrepression competent. J Biol Chem 2002, 277(9):6838-6845.

21. Reichenbach G, Starzinski-Powitz A, Sloane BF, Doll M, Kippenberger S, Bernd A, Kaufmann R, Meissner M: PPARalpha agonist Wy14643 suppresses cathepsin B in human endothelial cells via transcriptional, post-transcriptional and post-translational mechanisms. Angiogenesis 2013, 16(1):223-233.

22. Rizvi YQ, Mehta CS, Oyekan A: Interactions of PPAR-alpha and adenosine receptors in hypoxia-induced angiogenesis. Vasc Pharmacol 2013, 59(5-6):144-151

23. Hu Y, Chen Y, Ding L, He X, Takahashi Y, Gao Y, Shen W, Cheng R, Chen Q, Qi X, Boulton ME, Ma JX: Pathogenic role of diabetes-induced PPAR-alpha down-regulation in microvascular dysfunction. Proc Natl Acad Sci U S A 2013, 110(38):15401-15406.

24. Li Z, Kruijt JK, van der Sluis RJ, Van Berkel TJ, Hoekstra M: Nuclear receptor atlas of female mouse liver parenchymal, endothelial, and Kupffer cells. Physiol Genomics 2013, 45(7):268-275.

25. Rakhshandehroo M, Hooiveld G, Muller M, Kersten S: Comparative analysis of gene regulation by the transcription factor PPARalpha between mouse and human. PLoS One 2009, 4(8):e6796.

26. Szalowska E, van der Burg B, Man HY, Hendriksen PJ, Peijnenburg AA: Model steatogenic compounds (amiodarone, valproic acid, and 
tetracycline) alter lipid metabolism by different mechanisms in mouse liver slices. PLoS One 2014, 9(1):e86795.

27. Rakhshandehroo M, Sanderson LM, Matilainen M, Stienstra R, Carlberg C, de Groot PJ, Muller M, Kersten S: Comprehensive analysis of PPARalphadependent regulation of hepatic lipid metabolism by expression profiling. PPAR Res 2007, 2007:26839.

28. Gentleman RC, Carey VJ, Bates DM, Bolstad B, Dettling M, Dudoit S, Ellis B, Gautier L, Ge Y, Gentry J, Hornik K, Hothorn T, Huber W, lacus S, Irizarry R, Leisch F, Li C, Maechler M, Rossini AJ, Sawitzki G, Smith C, Smyth G, Tierney L, Yang JY, Zhang J: Bioconductor: open software development for computational biology and bioinformatics. Genome Biol 2004, 5(10):R80.

29. Qu Y, He F, Chen Y: Different effects of the probe summarization algorithms PLIER and RMA on high-level analysis of Affymetrix exon arrays. BMC Bioinformatics 2010, 11:211.

30. Breitling R, Armengaud P, Amtmann A, Herzyk P: Rank products: a simple, yet powerful, new method to detect differentially regulated genes in replicated microarray experiments. FEBS Lett 2004, 573(1-3):83-92.

31. Dennis G Jr, Sherman BT, Hosack DA, Yang J, Gao W, Lane HC, Lempicki RA: DAVID: Database for Annotation, Visualization, and Integrated Discovery. Genome Biol 2003, 4(5):3.

32. da Huang W, Sherman BT, Lempicki RA: Systematic and integrative analysis of large gene lists using DAVID bioinformatics resources. Nat Protoc 2009, 4(1):44-57.

33. Oliveros JC: VENNY. An interactive tool for comparing lists with Venn Diagrams. In [http://bioinfogp.cnb.csic.es/tools/venny/]

34. da Huang W, Sherman BT, Lempicki RA: Bioinformatics enrichment tools: paths toward the comprehensive functional analysis of large gene lists. Nucleic Acids Res 2009, 37(1):1-13.

35. Glass CK, Olefsky JM: Inflammation and lipid signaling in the etiology of insulin resistance. Cell Metab 2012, 15(5):635-645.

36. Hong F, Breitling R: A comparison of meta-analysis methods for detecting differentially expressed genes in microarray experiments. Bioinformatics 2008, 24(3):374-382.

37. Hong F, Breitling R, McEntee CW, Wittner BS, Nemhauser JL, Chory J: RankProd: a bioconductor package for detecting differentially expressed genes in meta-analysis. Bioinformatics 2006, 22(22):2825-2827.

38. Godoy P, Hewitt NJ, Albrecht U, Andersen ME, Ansari N, Bhattacharya S, Bode JG, Bolleyn J, Borner C, Bottger J, Braeuning A, Budinsky RA, Burkhardt B, Cameron NR, Camussi G, Cho CS, Choi YJ, Craig Rowlands J, Dahmen U, Damm G, Dirsch O, Donato MT, Dong J, Dooley S, Drasdo D, Eakins R, Ferreira KS, Fonsato V, Fraczek J, Gebhardt R, et al: Recent advances in 2D and $3 \mathrm{D}$ in vitro systems using primary hepatocytes, alternative hepatocyte sources and non-parenchymal liver cells and their use in investigating mechanisms of hepatotoxicity, cell signaling and ADME. Arch Toxicol 2013, 87(8):1315-1530.

39. Tamura K, Ono A, Miyagishima T, Nagao T, Urushidani T: Profiling of gene expression in rat liver and rat primary cultured hepatocytes treated with peroxisome proliferators. J Toxicol Sci 2006, 31(5):471-490.

40. de Graaf IA, Olinga P, de Jager MH, Merema MT, de Kanter R, van de Kerkhof EG, Groothuis GM: Preparation and incubation of precision-cut liver and intestinal slices for application in drug metabolism and toxicity studies. Nat Protoc 2010, 5(9):1540-1551.

41. Hasmall S, James N, Hedley K, Olsen K, Roberts R: Mouse hepatocyte response to peroxisome proliferators: dependency on hepatic nonparenchymal cells and peroxisome proliferator activated receptor alpha (PPARalpha). Arch Toxicol 2001, 75(6):357-361.

42. Fang X, Zou S, Zhao Y, Cui R, Zhang W, Hu J, Dai J: Kupffer cells suppress perfluorononanoic acid-induced hepatic peroxisome proliferatoractivated receptor alpha expression by releasing cytokines. Arch Toxicol 2012, 86(10):1515-1525.

43. Stienstra R, Saudale F, Duval C, Keshtkar S, Groener JE, van Rooijen N, Staels B, Kersten S, Muller M: Kupffer cells promote hepatic steatosis via interleukin-1beta-dependent suppression of peroxisome proliferatoractivated receptor alpha activity. Hepatology 2010, 51(2):511-522.

44. Elvevold K, Smedsrod B, Martinez I: The liver sinusoidal endothelial cell: a cell type of controversial and confusing identity. Am J Physiol Gastrointest Liver Physiol 2008, 294(2):G391-G400.

45. Sandoval A, Fraisl P, Arias-Barrau E, Dirusso CC, Singer D, Sealls W, Black PN: Fatty acid transport and activation and the expression patterns of genes involved in fatty acid trafficking. Arch Biochem Biophys 2008, $477(2) \cdot 363-371$.
46. Guo L, Li SY, Ji FY, Zhao YF, Zhong Y, Lv XJ, Wu XL, Qian GS: Role of Angptl4 in vascular permeability and inflammation. Inflamm Res 2014, 63(1):13-22

47. Mehrotra D, Wu J, Papangeli I, Chun HJ: Endothelium as a gatekeeper of fatty acid transport. Trends Endocrinol Metab 2014, 25(2):99-106.

48. Record M, Carayon K, Poirot M, Silvente-Poirot S: Exosomes as new vesicular lipid transporters involved in cell-cell communication and various pathophysiologies. Biochim Biophys Acta 2014, 1841(1):108-120.

49. Iglesias J, Barg S, Vallois D, Lahiri S, Roger C, Yessoufou A, Pradevand S, McDonald A, Bonal C, Reimann F, Gribble F, Debril MB, Metzger D, Chambon P, Herrera P, Rutter GA, Prentki M, Thorens B, Wahli W: PPARbeta/ delta affects pancreatic beta cell mass and insulin secretion in mice. J Clin Invest 2012, 122(11):4105-4117.

50. Banni S, Carta G, Murru E, Cordeddu L, Giordano E, Marrosu F, Puligheddu M, Floris G, Asuni GP, Cappai AL, Deriu S, Follesa P: Vagus nerve stimulation reduces body weight and fat mass in rats. PLoS One 2012, 7(9):e44813.

51. Bernal-Mizrachi C, Xiaozhong L, Yin L, Knutsen RH, Howard MJ, Arends JJ, Desantis P, Coleman T, Semenkovich CF: An afferent vagal nerve pathway links hepatic PPARalpha activation to glucocorticoid-induced insulin resistance and hypertension. Cell Metab 2007, 5(2):91-102.

52. Reddy JK, Rao MS, Azarnoff DL, Sell S: Mitogenic and carcinogenic effects of a hypolipidemic peroxisome proliferator, [4-chloro-6-(2,3-xylidino)-2pyrimidinylthio]acetic acid (Wy-14, 643), in rat and mouse liver. Cancer Res 1979, 39(1):152-161.

53. Karam WG, Ghanayem BI: Induction of replicative DNA synthesis and PPAR alpha-dependent gene transcription by Wy-14 643 in primary rat hepatocyte and non-parenchymal cell co-cultures. Carcinogenesis 1997, 18(11):2077-2083.

54. Guo L, Fang H, Collins J, Fan XH, Dial S, Wong A, Mehta K, Blann E, Shi L, Tong W, Dragan YP: Differential gene expression in mouse primary hepatocytes exposed to the peroxisome proliferator-activated receptor alpha agonists. BMC Bioinformatics 2006, 7(Suppl 2):S18.

doi:10.1186/1471-2164-15-1106

Cite this article as: Szalowska et al:: Transcriptomic signatures of peroxisome proliferator-activated receptor a (PPARa) in different mouse liver models identify novel aspects of its biology. BMC Genomics 2014 15:1106.

\section{Submit your next manuscript to BioMed Central and take full advantage of:}

- Convenient online submission

- Thorough peer review

- No space constraints or color figure charges

- Immediate publication on acceptance

- Inclusion in PubMed, CAS, Scopus and Google Scholar

- Research which is freely available for redistribution 